\title{
Breakfast Habits and It's Relationship to Body Mass Index, Cognitive Function among Final Year Medical Students
}

\section{Guwani Liyanage*, Siriwardana HD, Wettasinghe CA, Kumarasiri MKHN and Niwanthika TKI}

Department of Paediatrics, University of Sri Jayewardenepura, Sri Lanka

*Corresponding author: Guwani Liyanage, Department of Paediatrics, University of Sri Jayewardenepura, Sri Lanka, Tel: 0094773593785; Email: guwanil@yahoo.co.uk

Received date: June 05, 2017; Accepted date: June 12, 2017; Published date: June 18, 2017

Copyright: @ 2017 Liyanage G, et al. This is an openaccess article distributed under the terms of the Creative Commons Attribution License, which permits unrestricted use, distribution, and reproduction in any medium, provided the original author and source are credited

\begin{abstract}
Background: Balanced and healthy nutrition is needed in order to avert adverse effects of poor eating practices. Children and adults often miss breakfast due to many reasons including lack of time. Evidence indicates that breakfast consumption is more beneficial than skipping breakfast following a long overnight fast. Its effect on cognitive function is still under debate. Our aim was to conduct a preliminary study to investigate breakfast habits and its effect of certain aspects of cognition in medical students in a university in Colombo, Sri Lanka.
\end{abstract}

Methods: This study was a descriptive cross-sectional study. We assessed breakfast eating practices of final year medical students. Self-administered and questionnaire and trail making test for visual attention, task switching, speed of processing, and executive functioning were used as study instruments.

Results and Conclusions: We recruited 121 clinical students. Majority (55.4\%) skipped breakfast at least one or more days per week. Most consumed rice or wheat flour based meals and snacks and only a minority consumed cereals. We did not find any significant difference in trail making test between the two groups of students who skipped and consumed breakfast. A more comprehensive study exploring this topic is recommended.

Keywords: Students; Medical attention; Breakfast habits; Sri Lanka; Trail making test; Body mass index; Cognition

\section{Background}

Generally breakfast (BF) is labelled as the most important meal of the day. It follows the longest period of fasting. Therefore, missing out breakfast could result in decreased amount of nutrients for metabolism. Quality of the breakfast is also important to supply essential nutrients. Cereal based meals provide vitamins and minerals and they are lower in fat [1]. Regular whole grain or high fiber breakfast consumption prevents obesity. It lowers the risk of diabetes and cardiovascular diseases as well [2].

A systematic review on effect of breakfast consumption on cognitive function has concluded that there are definite advantages in breakfast consumption and the positive effects are more evident in children when their nutritional status is compromised [3]. Other studies have shown positive effects of breakfast consumption on visual and auditory short-term memory, recall and spatial memory [4,5]. Some studies have reported that there aren't any significant effects on cognitive functions [6,7]. Further, not many studies have shown that skipping breakfast affects tasks requiring attention and concentration [8,9]. Differences in study design, type of sample population, cognitive function assessment procedures might have contributed to these inconsistencies seen in these reports.

The government of Sri Lanka has taken initiatives to provide breakfast for school children free of charge. However, there is dearth of evidence available locally, investigating breakfast habits and effect of breakfast skipping/ type of breakfast on cognitive function or school performance. Further, investigating breakfast habits of individuals from certain streams of studies and occupations with busy schedules and high academic demand which requires the ability to sustain attention for long periods of time is as important as investigating school children. Thus, medical undergraduates who have a high chance of missing meals due to their busy schedules especially during their final year of clinical training are worth exploring. There are few observational studies on breakfast habits of medical students conducted in other countries $[10,11]$. However, there are no published studies on this topic to date available locally. Further, in a focus group discussion, medical students expressed that lack of time due to variety of compulsory training sessions, rigid time schedules make them miss out their breakfast. Thus, this is a pilot study aimed at investigating breakfast habits and its effect on some aspects of cognitive functions in final year medical students in a leading university in Colombo, Sri Lanka.

\section{Methods}

This is a descriptive, cross sectional, analytical study conducted in Colombo South Teaching Hospital among final year medical students in 6 major specialties (Paediatrics, Medicine, Gynaecology \& Obstetrics, Surgery, Psychiatry and Family Medicine). All the students (150) in final year were invited for the study. Of them $121(80.7 \%)$ participated.

The study was conducted in a quiet students' room. Written and verbal explanation of the study procedure was given in small groups of 8 to 10 students. Informed consent was obtained after explaining the procedure. Students who were absent on the day of assessment and students having chronic medical or surgical illnesses were excluded. 
Citation: Liyanage G, Siriwardana HD, Wettasinghe, Kumarasiri MKHN, Niwanthika TKI (2017) Breakfast Habits and It's Relationship to Body Mass Index, Cognitive Function among Final Year Medical Students. J Gen Pract (Los Angel) 5: 311. doi:10.4172/2329-9126.1000311

Page 2 of 4

Data collection was carried out in two stages. First, they were given a pre-tested, self-administered questionnaire followed by anthropometry measurements. In the second stage we used 'Trail making test' to assess some aspects of cognition. It is a simple test assessing visual attention, task switching, and speed of processing and executive functioning [12].

Self-administered questionnaire contained questions pertaining to demographic details, place of residence at present, breakfast consumption habits including type of food, knowledge/perception on complications of missing breakfast and reasons for missing breakfast. Fine tuning to the questionnaire were made following a pilot study. Height $(\mathrm{cm})$ and weight $(\mathrm{kg})$ were measured by a trained investigator and BMI was calculated. BMI was expressed in four categories as per the CDC (Center for disease control and prevention) guidelines (underweight-BMI $<18.5$, normal weight-BMI between 18.5 and 24.9, overweight- BMI between 25 and 29.9, and obese-BMI>30).

Trail making test was done on all the medical students who answered the questionnaire. It included time taken to connect numbers and letters in ascending order. In part A the participant connected the numbers in ascending order. In part B participant again connected numbers in an ascending pattern, but with the added task of alternating between the numbers and letters. Time taken to complete was documented. If a student made an error, that was pointed out right away and was permitted them to correct it.

Ethical clearance for the study was obtained from the Ethics committee of Sri Lanka College of Paediatricians.

\section{Statistical Analysis}

For analysis SPSS package version 16 was used. Continuous variables were expressed as means and standard deviations. Independent sample t-test was performed for comparisons. All results were taken as statistically significant when $p$ is $<0.05$.

\section{Results}

Results of 121 students were analysed. Mean age of the study sample was 25.45 years. Baseline characteristics of the study sample are given in (Table 1). The majority of the students were residing in university hostel or private boarding houses close to hospital. Majority had normal BMI. Majority had their breakfast on the day they were interviewed. ( $\mathrm{n}=97,80.2 \%)$.

\begin{tabular}{|c|c|c|}
\hline \multicolumn{2}{|l|}{ Characteristic } & \multirow{2}{*}{$\begin{array}{l}\text { Number (\%) } \\
46(38)\end{array}$} \\
\hline Gender & Male & \\
\hline \multirow[t]{2}{*}{ Place of residence } & Home & $47(38.8)$ \\
\hline & $\begin{array}{l}\text { University hostel } \\
\text { /Private boarding houses }\end{array}$ & $74(61.2)$ \\
\hline \multirow[t]{4}{*}{ BMI $\left(\mathrm{kg} / \mathrm{m}^{2}\right)$} & $\leq 18.5$ (underweight) & $23(19)$ \\
\hline & 18.5-24.99 (normal) & $79(65.3)$ \\
\hline & 25-29.99 (overweight) & $19(15.7)$ \\
\hline & $\geq 30$ (obese) & $0(0)$ \\
\hline Breakfast consumption & Skipped & $67(55.4)$ \\
\hline
\end{tabular}

Table 1: Baseline characteristics of the study sample.

\section{Pattern of breakfast consumption}

We assessed regularity of breakfast consumption. Programme for final year in our university is scheduled for 6 days, every week. Therefore, skipping breakfast was labeled as missed morning meal at least once, from Monday to Saturday in a week. In total, 55.4\% skipped breakfast at least a day. Of them, $21 \%$ had their breakfast $\leq 3$ days a week. Three students do not take breakfast at all. Type of breakfast is detailed in (Table 2). Considerable number consumed snacks for breakfast. Majority consumes a local meal based on rice or wheat flour. Only a minority had pulses/cereals for breakfast.

\begin{tabular}{|l|l|}
\hline Type of breakfast & Number (\%) \\
\hline Snacks (Tea buns/Chinese rolls/pastries etc.) & $35(28.9)$ \\
\hline Boiled rice/bread/string hoppers/milk rice (Local meals) & $85(70.2)$ \\
\hline Pulses (green gram/cow pea/chick pea) or ready to eat cereals & $10(8.3)$ \\
\hline Dairy products only & $01(0.8)$ \\
\hline Fruits only & $00(00)$ \\
\hline
\end{tabular}

Table 2: Type of food consumed for breakfast on most of the days. 
Page 3 of 4

Commonest reason for missing the morning meal was lack of time $(n=53,79.1 \%)$. None have mentioned that they miss breakfast due to financial reasons.

\section{Student perception on adverse effects of skipping breakfast}

Inquiry was made regarding their perception on possible adverse effects of missing the morning meal.

Majority thought that gastric irritation (97.1\%), hypoglycaemia $(81.8 \%)$, cognitive impairment $(56.2 \%)$, fatigability $(84.3 \%)$ and malnutrition $(64.5 \%)$ as adverse effects of not taking breakfast regularly.

\section{Performance of trail making test}

Mean time taken for trail A test was 22.66 seconds and trail B test was 47.78 seconds. For trail A females had better performance and this was significantly different from males $(\mathrm{p}=0.001)$. There was no statistically significant difference in trail $\mathrm{B}$ for males and females $(p=0.768)$; however males spent less time than females to compete trail B.

On the day of assessment 97 (80.2\%) had taken their breakfast. For them mean time gap from breakfast to cognitive test was 139 minutes. Trail making test score did not show any significant difference whether they had or haven't had BF before the interview (Table 3).

\begin{tabular}{|l|l|l|l|l|l|l|}
\hline Consumption Pattern & $\begin{array}{l}\text { Trail A } \\
\text { (mean time) }\end{array}$ & SD & p value & $\begin{array}{l}\text { Trail B } \\
\text { (mean time) }\end{array}$ & SD & p value \\
\cline { 1 - 5 } Consumed BF on the day of assessment & 22.64 & 5.46 & 0.98 & 46.09 & 17.54 & 0.55 \\
\cline { 1 - 3 } Did not consume BF on the day of assessment & 22.69 & 7.05 & & 48.39 & 13.68 & \\
\hline Time in seconds, SD- standard deviation & & & \\
\hline
\end{tabular}

Table 3: Comparison of time taken for trail making test between students who 'consumed' and 'did not consume' on the day of assessment.

\section{Level of nutrition}

None were obese. In our sample there were $15.7 \%$ and $19 \%$ students who are overweight and underweight respectively. There was no significant difference was found in mean BMI between breakfast skippers and non-skippers. In addition, BMI had no relationship to type of residence.

\section{Discussion}

Breakfast literally refers to having a meal after a long period of fasting. It is most often the first meal of the day before starting day's work. The type of breakfast varies from region to region. Our typical breakfast is mostly based on rice and wheat flour and it is energy dense. Now we have a wide range of preparations including ready to eat meals. Pulses are also considered a typical local breakfast and they are rich in proteins. However, pulses are not very popular in most of the households for breakfast, due to lengthy preparation time.

Most of our final year clinical students reside either in boarding houses or university hostels which are at close proximity to the teaching hospital. Students consume breakfast from places like way side boutiques or hospital canteen.

In the present study most of the medical students had a local meal based on boiled rice and wheat flour which was calorie dense. Pulses or ready to eat cereals which are high in fiber were not very popular. Although fruits for morning meal are a new trend, only one student preferred fruits. Significant percentage consumed unhealthy, energy dense, oily snacks for breakfast. The World Health Organization (WHO) states that this pattern of consuming carbohydrate dense diet appears to be a contributory factor to the increasing prevalence of obesity, which is a major risk factor for many non-communicable nutrition-related diseases such as hypertension, diabetes mellitus, cardiovascular diseases, stroke, and nutrition-induced cancer [13]. We do not know the reasons for choosing the type of food they consumed since we did not investigate that aspect. However, it is very likely that this type of eating behaviour will continue even when they graduate and start working in hospitals.

Our sample had higher percentage of BF skippers. In a study conducted in Ghana among clinical and pre-clinical medical students, breakfast skipping at least one day a week had been $72 \%$. Breakfast consumption rate is high in certain other countries. In United States $68.5 \%$ adolescents consumed breakfast regularly and almost $90 \%$ children and adults consumed breakfast in France [14,15].

The reasons given for skipping breakfast were as same as in most of the other studies. In a study among medical students in Ghana the commonest reason given was lack of time. Majority in our sample skipped BF due to lack of time although they perceived that there are adverse effects of skipping breakfast.

Education is free in state-funded universities in Sri Lanka. Students need family support for food and lodging since there are no loan schemes for university students. Few are offered part scholarships by the government on merit. However, financial reasons are not mentioned for missing BF in this study.

Studies have demonstrated that regular breakfast enhances cognitive performance in children; memory and attention in particular $[8,9,16]$. Although trail making performance was slightly better in the group who had breakfast in our study, they were not significantly different from the students who did not have breakfast on the day of interview. Group who missed BF was small. This could have affected this result. Another possible reason is difference in distribution of academic averages of students in the two groups which were compared.

Our study sample size was small, and thus, the current findings are not fully generalizable to the entire population of medical students. A more comprehensive, multi centre case control trial is required to assess the effect of skipping breakfast on other cognitive functions, academic performance, mood and memory of medical students. 
Citation: Liyanage G, Siriwardana HD, Wettasinghe , Kumarasiri MKHN, Niwanthika TKI (2017) Breakfast Habits and It's Relationship to Body Mass Index, Cognitive Function among Final Year Medical Students. J Gen Pract (Los Angel) 5: 311. doi:10.4172/2329-9126.1000311

Page 4 of 4

\section{Conclusions}

Skipping breakfast among final year medical students is common. Lack of time due to busy schedules is highlighted as a possible reason for this. Most had high calorie diet. That could be a possible reason for high rate of overweight in this sample. However, missing BF has no relationship to body mass index.

They perceived that skipping BF affects cognition. However, we could not show a significant difference in trail making test score in medical students who missed BF. A case controlled study is recommended to investigate skipping $\mathrm{BF}$ on neuro-cognitive effects and mood in our population of medical students. Further, exploring more into breakfast habits in a larger sample is worthwhile.

\section{References}

1. William PG (2014) The benefits of breakfast cereal consumption: A systematic review of the evidence base. Adv Nutr 5: 636S-673S.

2. Nicklas TA, Bao W, Webber LS, Berenson GS (1993) Breakfast consumption affects adequacy of total daily intake in children. J Am Diet Assoc 93: 886-891.

3. Hoyland A, Dye L, Lawton CL (2009) A systematic review of the effect of breakfast on the cognitive performance of children and adolescents. Nutr Res Rev 22: 220-243.

4. Wesnes KA, Pincock C, Richardson D, Helm G, Hails S (2003) Breakfast reduces declines in attention and memory over the morning in schoolchildren. Appetite 41: 329-331.

5. Mahoney CR, Taylor HA, Kanarek RB, Samuel P (2005) Effect of breakfast composition on cognitive processes in elementary school children. Physiol Behav 85: 635-645.

6. Dickie $\mathrm{NH}$, Bender AE (1982) Breakfast and performance in school children. Br J Nutr 48: 483-496.
7. Cromer B, Tarnowski K, Stein A, Harton P, Thornton D (1990) The school breakfast program and cognition in adolescents. J Dev Behav Pediatr 11: 295-300.

8. Adolphus K, Lawton CL, Dye L (2013) The effects of breakfast on behavior and academic performance in children and adolescents. Front Hum Neurosci 7: 425.

9. Conners CK, Blouin AG (1982) Nutritional effects on behavior of children. J Psychiatr Res 17: 193-201.

10. Ackuaku-dogbe EM, Abaidoo B (2014) Breakfast eating habits among medical students. Ghana Med J 48: 66-70.

11. Sun J, Yi H, Liu Z, Wu Y, Bian J, et al. (2013) Factors associated with skipping breakfast among Inner Mongolia Medical students in China. BMC Public Health 13: 42.

12. Plotek W, Lyskawa W, Kluzik A, Grzeskowiak M, Podlewski R, et al. (2014) Evaluation of the trail making test and interval timing as measures of cognition in healthy adults: Comparisons by age, education, and gender. Med Sci Monit 20: 173-181.

13. http://www.who.int/dietphysicalactivity/publications/trs916/ summary/en/

14. Deshmukh-Taskar PR, Nicklas TA, O’Neil C, Keast D, Radcliffe JD, et al. (2010) The relationship of breakfast skipping and type of breakfast consumption with nutrient intake and weight status in children and adolescents: The National Health and Nutrition Examination Survey 1999-2006. J Am Diet Assoc 110: 869-878.

15. Preziosi P, Galan P, Deheeger M, Yacoub N, Drewnowski A, et al. (1999) Breakfast type, daily nutrient intakes and vitamin and mineral status of french children, adolescents and adults. J Am Coll Nutr 18: 171-178

16. Wesnes K, Pincock C, Richardson D, Helm G, Hails S (2003) Breakfast reduces declines in attention and memory over the morning in school children. Appetite 41: 329-331. 